\title{
Female Power in Education: Is it a Reversal of Gender Gap?
}

\author{
Bouchaib Benzehaf \\ Chouaib Doukkali University, El Jadida, Morocco \\ e-mail: bbenz841@gmail.com
}

\begin{abstract}
Education today is increasingly being feminized with girls accounting for the large majority of the student population at all levels. This feminization is happening not only in terms of number of girls but also in terms of performance. The present paper reports on a comparative study that looked into the differences between girls' achievements and boys' achievements in high education. More specifically, the paper explores gender differences in written linguistic proficiency by analyzing a sample of high school students' pieces of writing in English. The research sample consisted of 130 high school students in the city of El Jadida, 59 males and 71 females. Using Hunt's T-units as a method of language measurement, the paper outlines gender differences in the sample in terms of accuracy, fluency and complexity. Results showed that girls significantly outperformed boys in different aspects of writing, thereby suggesting a reversal of gender inequality. However, care must be taken so that these differences which favor girls are not misinterpreted in such a way as to reproduce traditional gender inequalities in educational institutions (for instance, some people are advancing the idea that boys are differently, not deficiently, literate). In light of the results, the paper ends with recommendations for justice to be done to female students as well as for the adoption of best classroom management practices that maximise all students' achievements.
\end{abstract}

Keywords: gender, gender reversal, achievement, written competence 


\section{INTRODUCTION}

Gender inequality has been defined as unequal treatment of individuals based on their gender, attributed to differences in socially constructed gender roles. In this context, Beauvoir (1973: 301) says that "one is not born, but rather becomes, a woman". This statement distinguished between sex, the anatomically given aspect of the female body, and gender, the culturally acquired aspect of the female body or the acculturation process that the body of the female undergoes.

In schools, there has been a long-standing gender gap with boys being favoured over girls. For instance, at the beginning of the previous century, girls couldn't go to school or couldn't continue their schooling in case they went to school as priority always went to boys when school fees were short. Parents reasoned that girls were expected to marry and give birth to children while boys were expected to become breadwinners. Even when both sexes went to school, it was pronounced that boys were more intelligent and fared better than girls in different subjects.

The first wave of feminism was, therefore, focused on eliminating these sort of gaps besides the suffrage right. With time, efforts of the proponents of women's rights did bear fruit, and tremendous progress has been made since the first wave; the traditional gap closed and a discourse of equality was launched that led to more girls going to school. Nowadays, education is being feminized not only in terms of number of girls going to school, but also and mainly in terms of increased performance on the part of girls.

In Morocco, too, more girls are going to school today than ever before. In spite of the fact that the Gender Parity Index still shows a slight favoritism for boys in school enrolments (in 2012 for instance, the index was 0.91 meaning that more boys than girls were being enrolled in school), higher repetition and dropout rates among boys lead to higher numbers of girls in advanced stages of education, namely in high and higher education.

Thus, a rapid increase in female educational attainment has become a striking trend in education in the latest decades. Such a discourse of girls' increased achievements is being pitted against another discourse of boys' underachievement. Girls' effortful learning and less disruptive behavior have been designated as key factors in girls' increased performance while boys' underachievement has been attributed mainly to their disruptive behaviour and 'anti-school culture'. Owing to this female advantage in school achievements, gender is being recognized as a factor in determining student performance besides other traditionally decisive factors like motivation and ability.

Against this backdrop, the present study is a contribution to the debate on gender equality/inequality in educational achievements. The paper is motivated by the observation that girls are becoming more successful in schools, thus fueling a discourse of girl power and problematizing traditional feminist discourses of gender inequality. This observation triggered our curiosity to conduct the present study and find out whether the observation has a physical reality and girls are really achieving today in such a way as to challenge traditional gender roles and stereotypes. 
More specifically, the study aims to explore gender differences in school achievements in high school with a view to documenting the latest gender trends in education. It wishes to clearly determine whether the traditional disparities in school performance between boys and girls persist, or the stereotypical superiority of boys no longer holds. In particular, it addresses the following research questions:

1. Is there a gender gap in students' writing ability (and in favour of whom)?

2. Is the difference statistically significant?

3. Do male and female students perceive each other's abilities similarly?

\section{LITERATURE REVIEW}

"Gender gaps in education" is an old issue. Traditionally, girls have suffered from a discourse of inequality with boys. On the basis of this discourse, they could not go to school or stay at school when they went to it. They have also being designated as less intelligent than boys. According to Lips (1997), prior to the $20^{\text {th }}$ century, it was a commonly held view that men were intellectually superior to women.

However, a number of countries, including Morocco, have made tremendous progress since then. Gender disparities are not only narrowing in many parts of the world, but turning in favour of girls. According to Lips (1997), there are no overall differences now in educational achievement, though commonly held myths about gender continue to make girls less able in at least some cognitive tasks. However, different studies have been conducted which proved that girls are not inferior to boys. On the contrary, most studies showed that girls are doing better than boys in schools.

Hyde (2005) performed 46 meta-analyses, and found that $78 \%$ of effect sizes for differences were in the small or close-to-zero range. Only few main differences between the two sexes appeared in the studies analysed. Further, these small differences fluctuated with age, growing smaller or larger at different times in life. Thus, Hyde concluded that there were more similarities than differences between the two sexes. On the basis of this observation, she developed her famous "Gender Similarities Hypothesis" according to which boys and girls are more alike than different on most psychological variables.

In a subsequent study, Hyde, Lindberg, Linn, Ellis, and Williams (2008) investigated large amounts of data (7 million students). Consistent with the findings of the previous study, the researchers reported again that traditional gender differences in math performance no longer hold, with the mean for gender differences being trivial $(\mathrm{d}=-0.05)$. As a result, the researchers called for thoughts on gender gaps to be revised in such a way as to do justice to girls.

In contrast to the findings of the studies by Hyde (2005) and Hyde et al (2008) which proved absence of gender differences in most school subjects, other studies showed gender differences but in favour of girls. In point of fact, stable female advantages were reported in most courses by different researchers. For instance, Fergusson and Horwood (1997) examined gender differences in educational outcomes from school entry to age 18. They looked at the results of standardized testing, teacher ratings of student performance, and the final outcomes measured by 
school certificate success. Three major conclusions were evident: i) in all educational stages, males achieved less than females. Gender differences were evident in the results of standardised testing, teacher ratings of school performance and in the school leaving outcomes of the participants of the study. ii) These gender differences in educational achievement could not be explained by gender differences in intelligence since boys and girls had very similar IQ test scores. iii) There were gender related differences in classroom behaviours with males being more prone to disruptive and inattentive classroom behaviours. Thus, the cause for male underachievement was not low IQs but ill behaviour in classrooms.

Another study which also proved female advantages but this time exclusively in writing was conducted by Kanaris (1997). In particular, Kanaris (1999) looked closely at differences in writing between boys and girls and noted that girls wrote longer more complex texts that contained more subordinate clauses and a wider range of adjectives. Kanaris argued, therefore, that girls were more skilled both at word and text level. She also noted the existence of an identifiable gender characteristic in writing which would, she says, develop further in future.

Kenney-Benson, Pomerantz, Ryan, and Patrick (2006) have drawn attention to the fact that girls are surpassing boys in school grades even in stereotypically masculine subject areas like maths and science. Interestingly, these researchers went beyond documenting girls' academic excellence to investigate causes for it. In particular, they examined how each sex approaches school work. The main variables were achievement goals, classroom behaviour, learning strategies, and self-efficacy. The findings showed that girls were more likely than boys to hold mastery over performance goals and to refrain from disruptive classroom behaviour. Mastery goals emphasize understanding the material, whereas performance goals emphasize marks. Hence, learning strategies accounted for girls' advantages in terms of grades.

Jones and Myhill (2007) explored gender differences and similarities in linguistic competence in writing. Based on the results of a large-scale analysis of the linguistic characteristics of secondary-aged writers, the researchers reported the existence of evidence, though small, which supports the argument that boys and girls are differently literate. They noted small statistically significant differences at sentence level and at text level. The differences were considerably fewer than those identified by achievement level which showed that girls outperformed boys.

Similarly, Geisler and Pardiwalla (2010) documented girls' academic advantages for girls in all courses and in all stages of education. The researchers reported that boys' underachievement and underparticipation at both primary and secondary levels was well established. They also noted higher dropout rates, higher levels of truancy, and greater discipline problems among boys than among girls, which could account for boys' lagging performance.

In another meta-analysis which spanned data from 1914 to 2011 and which evaluated gender differences in a wide variety of subjects, Voyer and Voyer (2014) reported a stable female advantage extending to all school subjects (language, math, science, ...). The researchers have also noted that this female advantage "seems to be a well-kept secret considering how little attention it has received as a global phenomenon" (p. 1191). According to the researchers, although the reported gender 
differences would be classified as small based on Cohen's (1988) categorization of effect sizes (the values were kept within 0.2 indicating a small effect size), they were so consistent that they should not be ignored.

Along the same lines, Reynolds, Scheiber, Hajovsky, Schwartz, and Kaufman (2015) confirmed females' increased performance compared with boys. Using a large, nationally stratified sample of children and adolescents, the researchers investigated gender differences in writing and concluded that writing was an academic subject that may be an exception to Hyde's similarity hypothesis. They reported that girls outperformed boys, scoring higher mainly on spelling and written expression, with effect sizes inconsistent with the gender similarities hypothesis.

\section{RESEARCH METHOD}

The present study follows an observational exploratory design. Exploratory research refers to research conducted to explore, clarify and define the nature of a phenomenon. The objective of this study is to explore gender differences in writing, and if they are statistically significant. Another objective is to explore how each sex perceives the other sex's abilities in writing.

\subsection{Setting and Participants}

The study was conducted in April 2015 in three different high schools all located within the province of El Jadida. The participants were 130 students in their first year at high school distributed between 59 boys and 71 girls. The slightly higher number of girls reflects the tendency of girls to participate in studies more readily than boys, but it does not affect the reliability of the conclusions as group means are calculated separately. Following is an brief overview of the setting and participants:

Table 1: Overview of the participants and participating schools

\begin{tabular}{l|c|c|c}
\hline School & N. of boys & N. of girls & $\begin{array}{c}\text { Total number } \\
\text { of students }\end{array}$ \\
\hline 6 November & 26 & 33 & 59 \\
\hline Chouaib Doukkali & 20 & 21 & 41 \\
\hline Moulay Abdella & 13 & 17 & 30 \\
\hline $\begin{array}{l}\text { Total number of } \\
\text { students }\end{array}$ & 59 & 71 & 130 \\
\hline
\end{tabular}

\subsection{Research Instruments}

Data collection tools consisted of a proficiency test (a free writing task) in addition to a question regarding the participants' views about students' abilities in writing. The proficiency test was responsible for identifying differences between boys and girls in writing as it provides concrete realisations regarding what learners can do in their language productions, whereas the question was in charge of determining the way each sex views the other sex. The question required the participants to nominate students who are good at the writing skill. 


\subsection{Data Analysis Method}

It is widely believed that L2 writing proficiency constructs are multicomponential in nature, and that the notions of complexity, accuracy and fluency can satisfactorily capture their principal dimensions (e.g. Ellis, 2003, 2008; Ortega, 2003; Skehan, 1998). These dimensions are believed to best describe language performance in general and determine variation among students. They are most frequently used as dependent variables to assess variation with respect to independent variables such as attained level of acquisition or the features of a language task. Thus, we adopted CAF (complexity, accuracy and fluency) dimensions to analyse students' written pieces in this study. To reduce the subjectivity usually associated with holistic ratings, the present study used a more objective measure, namely, Hunt's T-units (1966).

To measure CAF constructs in students' writing, we used Hunts' $\mathrm{T}$ units defined as one main clause with all subordinate clauses attached to it (Hunt, 1966). According to Hunt, the length of a T-unit determines the cognitive development of a learner, thereby providing a satisfactory and stable index of language development. Further, T-units have been found to be more reliable indicators of language measurement. They have proved to be better than scoring rubrics which showed their subjectivity as rarely would two scorers agree on one mark for a single test. Tunits involve a fairly high degree of inter-rater reliability with regard to identification of units and unit boundaries and thus are more reliable; different scorers would rarely produce different analyses. The following table describes how these dimensions were operationalized in the study

Table 2: CAF measures adopted in the analysis of students' written products

\begin{tabular}{l|l|l}
\hline Fluency & Accuracy & Complexity \\
\hline total number of words & $\begin{array}{l}\text { number of error-free T- } \\
\text { units }\end{array}$ & $\begin{array}{l}\text { mean number of } \\
\text { words per T-unit }\end{array}$ \\
\hline total number of T-units & $\begin{array}{l}\text { error free T-units per } \\
\text { total number of T-units } \\
\text { ratio }\end{array}$ & $\begin{array}{l}\text { mean number of } \\
\text { clauses per T-unit }\end{array}$ \\
\hline
\end{tabular}

The obtained data was fed into the Statistical Package for the Social Sciences (SPSS) to be analysed. Descriptive statistics was used to generate means, percentages and standard deviations. Additionally, an independent samples t-test was used to test for the significance of the differences between boys and girls. This test is the most common form of t-test that helps us know if the difference between two groups is unlikely to have occurred because of random chance in sample selection.

\section{FINDINGS}

The study looked into differences between boys and girls in writing. The first research question addressed the issue of whether there is a gender gap in students' writing ability, and in case it existed, it was in favor of whom. 
Table 3 below shows clearly that girls achieved higher than boys in fluency, represented by word number and T-unit number. The mean obtained by girls was 56,50 compared to only 40,27 by males and 9,14 against 6,37 successively. In accuracy, girls' superiority was again obvious as they scored 4,77 against 2,44 obtained by males in error-free T-units and ,47 against ,34 by males in the ratio of error-free T-unit to total number of T-units. In complexity, however, only slight differences emerged with boys scoring 6,51 in words per T-unit and girls obtaining 6,49 ; similarly, in number of clauses per T-unit, the difference was very slight as girls obtained 1,08 and males scored 1,05.

Table 3: Results by gender (CAF measures)

\begin{tabular}{l|c|c|c|c}
\hline \multicolumn{1}{c|}{ Item } & Gender & Mean & $\begin{array}{c}\text { Standard } \\
\text { deviation }\end{array}$ & $\begin{array}{c}\text { Standard } \\
\text { error mean }\end{array}$ \\
\hline \multirow{2}{*}{ Word number } & male & 40,27 & 7,90 & 1,02 \\
\cline { 2 - 5 } \multirow{2}{*}{ T-unit number } & Female & 56,50 & 10,72 & 1,27 \\
\hline \multirow{2}{*}{ Error free T-units } & Male & 6,37 & 1,53 &, 19 \\
\cline { 2 - 5 } & Female & 9,14 & 2,56 &, 30 \\
\hline \multirow{2}{*}{ Error free T-unit ratio } & Male & 2,44 & 1,82 &, 23 \\
\cline { 2 - 5 } & Female & 4,77 & 2,85 &, 33 \\
\hline \multirow{2}{*}{ Words per T-unit } & Male &, 34 &, 22 &, 02 \\
\cline { 2 - 5 } & Female &, 47 &, 21 &, 02 \\
\cline { 2 - 5 } $\begin{array}{l}\text { Number of clauses per T- } \\
\text { unit }\end{array}$ & Male & 6,51 & 1,33 &, 17 \\
\cline { 2 - 5 } & Female & 6,49 & 1,63 &, 19 \\
\hline
\end{tabular}

The second research question addressed the issue of the significance of the differences obtained in the measures of fluency and accuracy. To that end, an Independent-Samples T-test was conducted to compare the means obtained by girls and the means obtained by boys. There was a significant difference in the scores for males $(M=9,1532, S D=, 24169)$ and the scores for females $(M=9,5429, S D=, 58102)$; $\mathrm{t}(101)=-4,294, \mathrm{p}=, 000$. The $\mathrm{t}$ value is negative indicating that group 2 mean (girls' mean) is larger than group 1 mean (boys' mean).

Regarding the third research question, it addressed the issue of how each sex views the other sex's abilities in writing. To that end, a question was delivered to the participants which asked them to nominate the students who they thought were good at the writing skill. Notwithstanding girls' superiority in most areas of writing in particular and in language ability in general, answers came inconsistent with students' grades. $80,85 \%$ of the male participants nominated boys only while $71,42 \%$ of the female participants nominated girls and boys.

\section{DISCUSSION}

This study examined gender differences in one particular area, namely writing among high school students in their first year. The findings showed clearly that males were at a disadvantage compared with girls. A comparison of the mean scores 
showed that girls scored higher in fluency and accuracy but not in complexity. Besides, the difference between the mean of the male group and the mean of the female group has been found to be statistically significant according to Cohen's conventions. In complexity, however, there were no differences. Such an absence of gender differences in complexity may be attributed to the factor that students are at a level not yet exposed to complex sentences. May be in a more advanced educational stage such as in tertiary education, complexity would also produce itself as an area where girls achieve better than boys. Another reason may be linked to the nature of the topic which could have prevented students from displaying more complex levels in writing.

The findings obtained are consistent with the literature. For instance, Reynolds (2015) also reported female advantages in writing and concluded that even if we accept Hyde's Gender Similarities Hypothesis (2005), writing would offer itself as an exception. Along the same lines, the study conducted by Voyer and Voyer (2014) not only confirmed female advantages, but also extended them to all school subjects. In data spanning from 1914 to 2011, gender differences in favour of girls were consistent in different school subjects. The findings are also in line with English Proficiency Index, an international test which measures people's competency in English, according to which Moroccan girls scored 51.21 as compared to 48.17 by boys. Girls were closer to the global average while boys lagged far behind. Now, having documented girls' academic advantage in writing, the question that comes in order is: "what is the cause of such female increased performance?"

In the absence of tests on intelligence, we cannot claim that boys are less intelligent and we do not think that intelligence is the cause of boys' underachievement. More potent explanations suggest themselves. One such explanation is general school behavior with high rates of disruptive behaviour and high truancy levels among boys than girls according to the records at the administrations of the schools where the participants of this study belong. Probably male academic achievement would not be less than female academic achievement had boys been as well disciplined as girls. Such an explanation is also empirically based. It has been voiced, for instance, by Fergusson and Horwood (1997) and Kenney-Benson et al (2006). These researchers argue that boys' inattentive and disruptive behaviours account for their underachievement in school. In turn, Geisler and Pardiwalla (2010) noted a strong correlation between boys' underachievement and higher levels of truancy and discipline problems.

Another explanation may go to learning styles adopted by the two different sexes. Learning styles are applicable to all course areas and not only to writing, which is why girls are doing better than boys in all academic subjects. According to Kenney-Benson et al. (2006), the learning style adopted by females makes them more mastery and less performance-oriented and more attentive in class and less disruptive. Such positive attitudes to school work are likely to enhance grades as they foster more effortful learning and higher concentration levels.

Another possible explanation is grounded in the theoretical framework within which this study is situated, namely modernisation theory and value change that ensues from it. As girls are receiving more recognition, opportunities, freedom, 
equality and occupational options, they are striving to show that they are up to the challenges including school performance. Besides, girls are learning to construct their identity in newer, less domestic terms. While increased female participation in the paid workforce, break-up of traditional family units, and transformation of sex roles have a role to play in this shift, education offers the tools of change.

Consequently, female students are highly motivated and more focused on their studies. They are also adopting more positive attitudes to school work. Besides, girls can also be claimed to have higher aspirations than boys; they want to enroll in tertiary education and earn a higher degree while boys, in general, aim for a lower vocational degree or enrolment in the police force. Additionally, the presence of a high rate of female teachers in schools further motivates girls to work hard and have similar occupations.

Regarding the last research question, the findings indicated a peer-perception gap. This means that boys refused to recognize female achievements in school while girls' answers showed that they recognized boys' presence although boys were generally performing less well. One possible interpretation of this peer perception gap may be connected with the way boys are socialized. Boys probably have been educated into exercising bias against girls even if girls are high-achievers. This is an extension of female invisibility in society which we may paradoxically also use to explain female academic advantages by advancing the argument that girls' increased achievements are one way of making themselves visible and one way of resisting traditional gender roles mapped for women.

The peer perception gap provides us with evidence that there are gender stereotypes impacting on students and young people in general. Although girls are achieving better than boys and are more likely to go on to tertiary education, these advantages are not yet fully recognised by society as they should be and they do not yet fully translate into equality at home in particular and in society in general. Thus, what is happening in schools is an extension of what is happening outside school which underscores that notwithstanding women's achievements, males still refuse to acknowledge their skills. It also raises our attention to the fact that the opportunities women are benefiting from are still fragile and need consolidation.

\section{CONCLUSION: A REVERSAL OF GENDER GAP?}

This study set out to explore gender differences in the area of writing among high school students. More specifically, it examined differences in fluency, accuracy and complexity in a writing exercise administered to first year high school students from three different schools in El Jadida. It has been found out that girls steadily out-perform boys in academic areas, and the differences are highly noticeable, thus suggesting a reversal of the traditional gender gap. However, it has also been found out that a peer perception gap persists, with boys refusing to recognize girls' skills in spite of their higher grades.

Possible interpretations of female advantages at school go primarily to their good behaviours and attentiveness in classrooms. Other sources are connected with modernization theory which is responsible for the change of values in our society. Girls are being given more freedom, more opportunities and recognition for their 
merit in society. These are main factors motivating them to work harder and prove their worth in society. As to the peer perception gap, we interpreted it in light of the process of socialization that the boys are subject to at home.

While we commend girls for their academic performance, we also raise questions regarding the new gender gap because we cannot achieve sustainable development based on one half of the country's population. Indeed, the new gender gap should be a cause for concern to promote a discourse of "both sexes win" because no country shall progress if its half is idle. Unless action is taken, males will continue to perform below the level of females in all courses.

Lastly, the present study focused on writing. Such a focus is likely to limit the generalizability of the conclusions reached. Therefore, we recommend that other studies be conducted that explore gender differences in other school areas. Another important area for exploration in future studies is identifying the factors for the new pattern of boys' underachievement in school and addressing the needs of boys to bridge gender differences rather than reinforce them.

\section{RECOMMENDATIONS}

In light of the results obtained, there are a number of recommendations worth considering. The most pressing issue related to gender gaps is the lagging performance of boys and the peer perception gap. First, as girls have proved that they are not less able than boys, they need to be highly regarded, empowered and given opportunities. Consequently, a culture of socialization into not acknowledging girls' efforts even if girls score higher needs to be redressed. Second, care must be taken so that differences in favour of girls are not misinterpreted to reproduce traditional gender inequalities. Some people, for instance, are advancing the argument that boys are not deficiently literate but only differently literate. In this context, Cohen (1998) observes that women's accomplishments in language domains have hardly been recognised as intellectual advantages; on the contrary, they have historically been interpreted as shallow talkativeness providing evidence of innate inferiority to men who displayed more reserved and self-regulated verbal skills that testified to masculine intellectual strength.

Third, educational reforms should now give greater priority to boys' educational difficulties. More precisely, efforts should centre on best classroom management practices that address the issue of disruptive behaviour in a way that maximises all students' achievements. Boys need to be disciplined, attentive in class and less disruptive, and need to learn to focus on their studies. They need also to learn to set higher expectations and goals. We suggest that we should start this process by connecting with them and meeting them where they are. In this context, social networking technologies have to be channeled to the educational service.

Last but not least, while we recommend that sound policies should be put in place to consolidate women's rights and make them equal partners to men, the increased female achievement should not blind us to the girls who are left behind, namely, the girls who have been deprived of their right to go to school. We should not forget that the Gender Parity Index still shows a slight favoritism for boys in school enrolments, an issue that needs to be fixed immediately in order to bring all 
girls to school. Further, we should move beyond generalizing schooling to schoolage children to guarantee quality education to all so that everybody participates in the sustainable development of the country.

\section{REFERENCES}

Beauvoir, S. de (1973). The second sex. New York: Vintage Books.

Browne, A. (1994). The content of writing in the early years: Issues of gender. Reading, 28(3), 2-8.

Cahill, L. (2005). His brain, her brain. Scientific American 292(5), 40-47.

Cohen, M. (1998). 'A habit of healthy idleness': Boys' underachievement in historical perspective. In D. Epstein, J. Elwood, V. Hey, \& J. Maw (Eds.), Failing boys? Issues in gender and achievement (pp. 19-34). Milton Keynes, UK: Open University Press.

Dee, T. S. (2005). Teachers and the gender gaps in student achievement. Working Paper \#11660, National Bureau of Economic Research. www.nber.org/papers/w11660.

Ellis, R. (2003). The study of second language acquisition. Oxford: Oxford University Press.

Ellis, R. (2008). Task-based language learning and teaching. Oxford: Oxford University Press.

Fergusson, D. M. \& Horwood, L.J. (1997). Gender differences in educational achievement in a New Zealand birth cohort. New Zealand Journal of Educational Studies, 32(1), 83-96.

Geisler, G. \& Pardiwalla, M. (2010). Socialization patterns and boys' underperformance in Seychellois schools. Journal Statistique Africain, 11, 6284.

Halpern, D.F. (2000). Sex differences in cognitive abilities ( $3^{\text {rd }}$ ed.). Mahwah, NJ: Lawrence Erlbaum Associates.

Hunt, K. W. (1966). Recent measures in syntactic development. Elementary English, $43,732-39$.

Hyde, J. S. (2005). The Gender Similarities Hypothesis. American Psychologist, 60(6), 581-592.

Hyde, J., Lindberg, S.M., Linn, M.C., Ellis, A.B., \& Williams, C.C. (2008). Gender similarities characterize math performance. Science, 321, 494-495.

Jones, S. \& Myhill, D. (2007). Discourses of difference? Examining gender differences in linguistic characteristics of writing. Canadian Journal of Education, 30(2), 456-482.

Kanaris, A. (1999). Gendered journeys: Children's writing and the construction of gender. Language and Education, 13(4), 254-268.

Kenney-Benson, G. A., Pomerantz, E. M., Ryan, A. M., \& Patrick, H. (2006). Sex differences in math performance: The role of children's approach to schoolwork. Developmental Psychology, 42, 11-26.

Lips, H. M. (1997). Sex \& Gender: An Introduction ( $3^{\text {rd }}$ ed.). Mountain View, Calif.: Mayfield. 
Millard, E. (1997). Differently literate: Boys, girls and the schooling of literacy. London, UK: Falmer.

Ortega, L. (2003). Syntactic complexity measures and their relationship to L2 proficiency: A research synthesis of college-level L2 writing. Applied Linguistics, 24, 492-518.

Reynolds, M. R', Scheiber, C., Hajovsky, D. B., Schwartz, B., \& Kaufman, A. S. (2015). Is writing an exception to the gender similarities hypothesis? Journal of Genetic Psychology, 176(4), 211-234.

Skehan, P. (1998). A cognitive approach to language learning. Oxford: Oxford University Press.

Van Houtte, M. (2004). Why boys achieve less at school than girls: The difference between boys' and girls' academic culture. Educational Studies, 30(2), 159173.

Voyer, D. \& Voyer, D. S. (2014). Gender differences in scholastic achievement: A meta-analysis. Psychological Bulletin, 140(4), 1174-1204.

Weiner, G., Arnot, M. \& David, M. (1997). Is the future female? Female success, male disadvantage and changing gender patterns in education. In A. Halsey, P. Brown, H. Lauder \& A. Stuart-Wells (Eds), Education, culture, economy and society (pp. 620-630). Oxford: Oxford University Press.

Willingham, W. W. \& Cole, N.S. (1997). Gender and fair assessment. Mahwah, NJ: Lawrence Erlbaum Associates.

http://www.sociologyguide.com/education/education-and-modernization.php 